\title{
PHOTOGRAPHING TURKEY VULTURES AT MADGE LAKE
}

by Robert J. Long, Saskatchewan Museum of Natural History, Regina

Stuart Houston has recently recently reviewed the records of Turkey Vulture nests in Saskatchewan, which date back to 1893 and include, as the most recent of twelve known nests, one located near the U.S. border southwest of Regina in 1965 (Blue Jay, $27: 37-39$, 1969). Dr. Houston's report thus helps to fill in the gap in knowledge of the distribution of this species in Saskatchewan, for which Godfrey could give no definite indication in The birds of Canada (1966).

As early as 1942 Turkey Vulures were looked upon as an interesting feature of the wildlife of Madge Lake in Duck Mountain Provincial Park. They apparently nested on an island in Madge Lake in 1942, and they were reported as numerous as late as 1945 when as many as 30 could be seen soaring over the lake (Houston, op. cit., p. 38). They are still relatively abundant there, and I had some excellent opportunities to photograph them on visits made to the park in July and August of 1970. During those two months I was able to locate vultures almost daily in the vicinity of the refuse pits. On several occasions I counted 18 birds and once there were 24 present. They were usually perched in the trees around the dumps, or soaring overhead, but occasionally they were surprised on the ground, feeding. Generally they took flight more readily than the California and Ring-billed gulls, but were not as alert as the Ravens. On most evenings they congregated high in the trees a short distance from the clearing around the pits to roost for the night. On cold or damp mornings they could frequently be seen perched with wings outstretched, presumably to catch the warmth of the morning sun. They

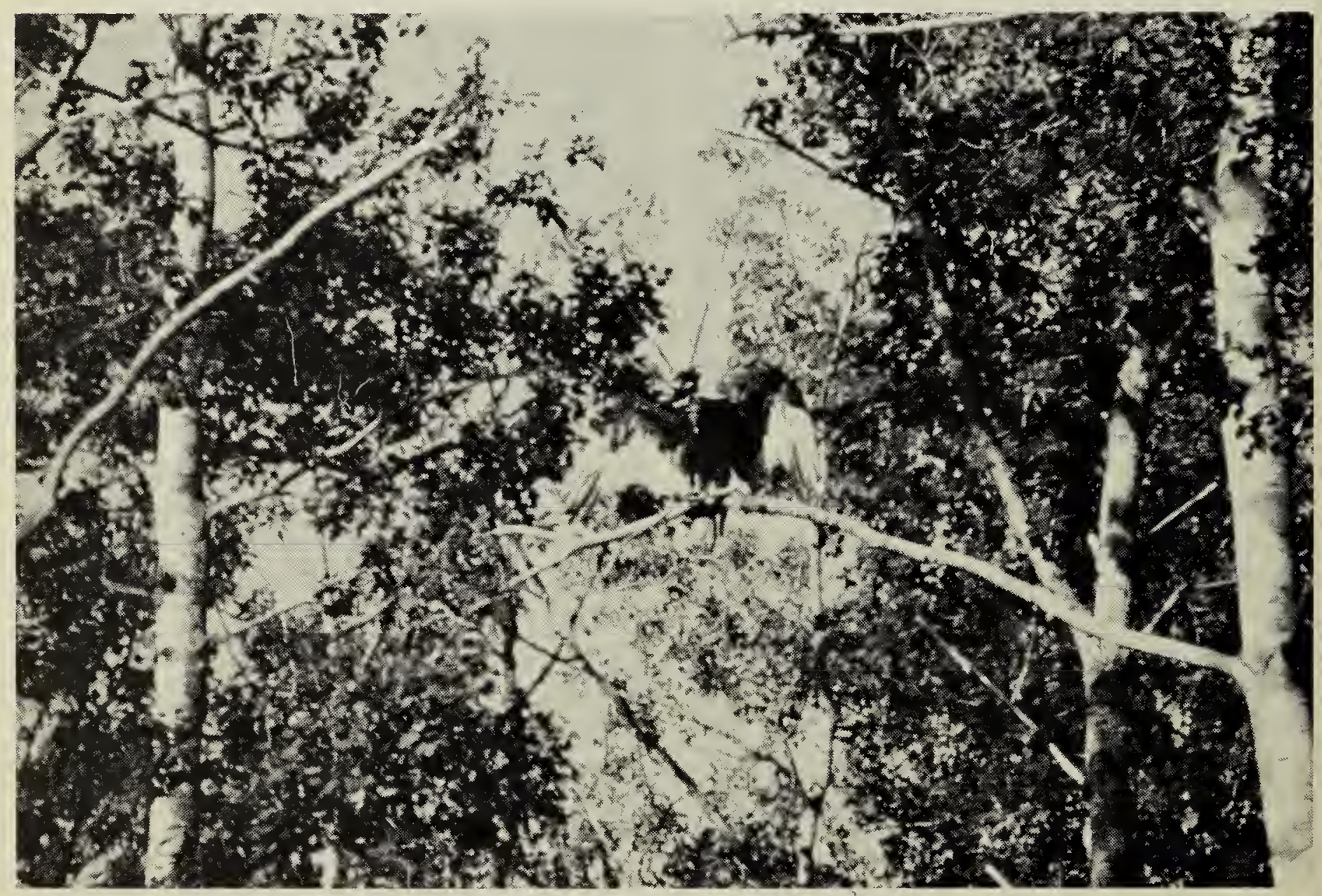

Turkey Vulture with wings outstretched 


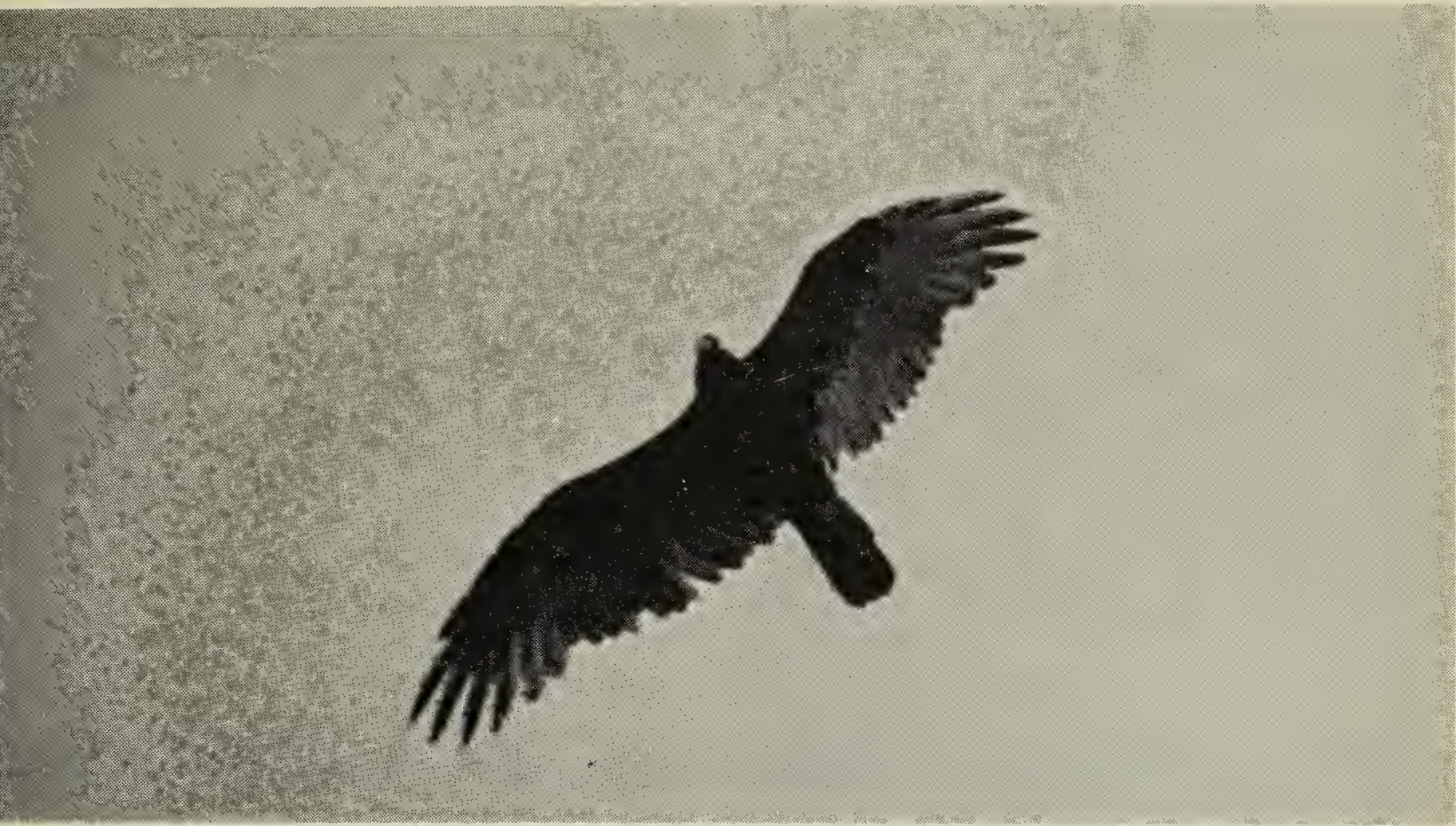

Turkey Vulture above Madge Lake, 1970

occasionally assumed this posture at other times of the day as well. Periodically they would disappear for several days but I was not able to determine where they went during these times.

The presence of so many Vultures in the Duck Mountain Park suggested breeding, but neither Fred Lahrman nor I could find any nests in the summer of 1970 on the islands in Madge Lake where the 1942 nest was reported.

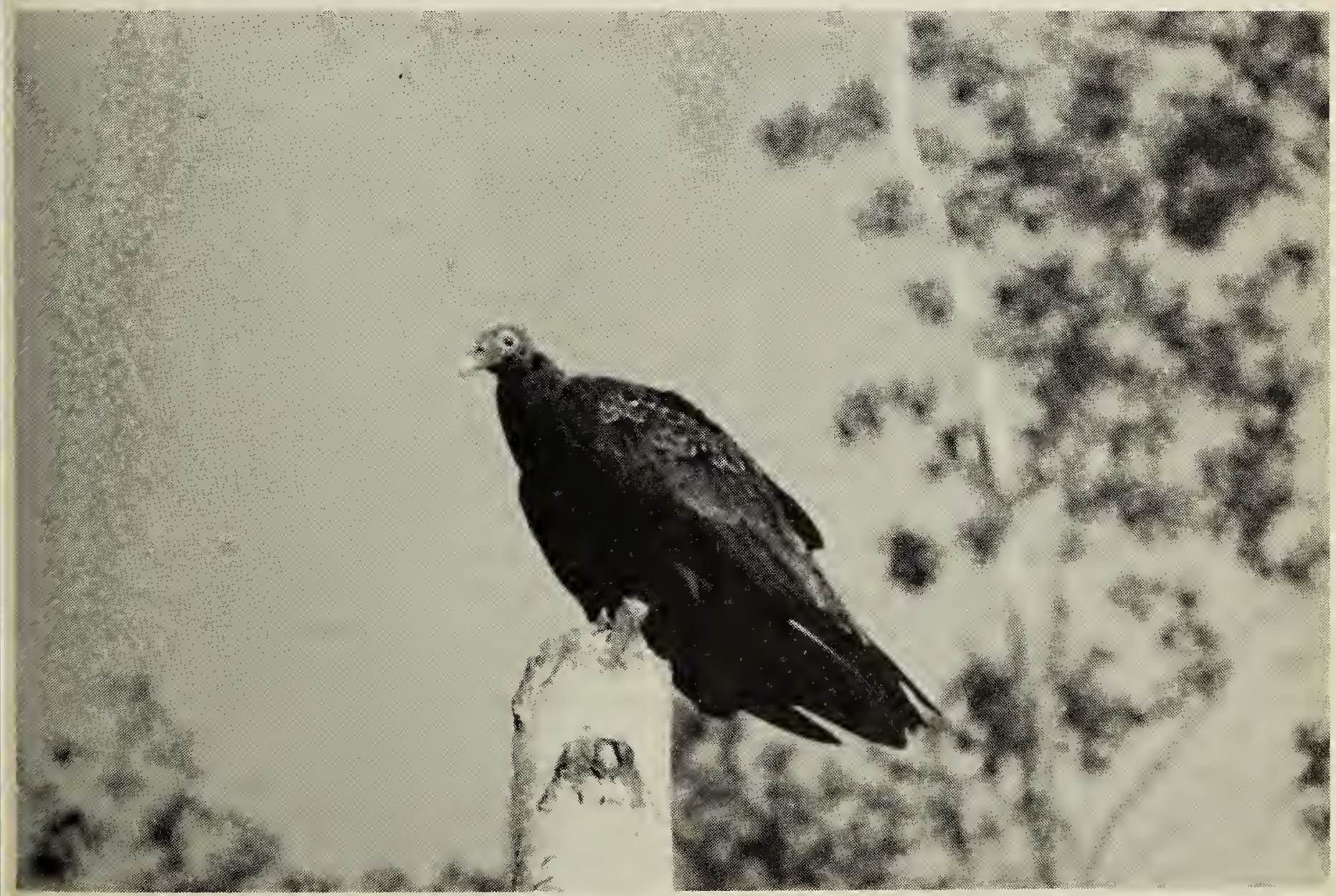

Turkey Vulture

Photos by Robert J. Long 